\title{
Yaşlı kalça kırıklarında sınıflama ve tedavi seçimindeki rolü
}

\author{
Classification of hip fractures and its role in treatment selection
}

\author{
Mustafa Yerli, Hakan Gürbüz
}

SBÜ Prof. Dr. Cemil Taşçıŏlu Şehir Hastanesi, Ortopedi ve Travmatoloji Kliniği, İstanbul

\begin{abstract}
Giderek yaşlanan dünya nüfusunda osteoporoza bağlı gelişen kalça kırı̆̆ı sayısı artmaktadır. Diğer kırık tiplerinde olduğu gibi, kalça kırıklarında da tabloyu daha iyi tanımlamak, uygulanacak tedavi yöntemine karar verebilmek ve ortak bir dil oluşturmak adına sınıflandırmalar yapılmıştır. Yaşı kalça kırıklı bir hastanın tedavisini planlarken mevcut sınıflama sistemlerinden yararlanabilmekteyiz. Ancak, mevcut sınıflama sistemlerinin hiçbiri hangi tip kırığa hangi tedaviyi uygulamamız gerektiğini kesin olarak belirtmemektedir. Zira kırık şeklinin tedavi çeşidine karar vermedeki rolü tek başına yetersiz olup hastanın yaşı, fonksiyonel durumu, ek hastalıkları gibi diğer ek faktörler de bu süreçle doğrudan ilişkilidir.
\end{abstract}

Anahtar sözcülkler: femur boyun kırığı; intertrokanterik kırık; Garden sınıflaması; Evans sınıflaması

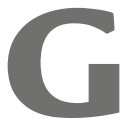
iderek yaşlanan dünya nüfusunda osteoporoza bağlı gelişen kalça kırığı sayısı artmaktadır. Tüm dünyada bir yılda gelişen kalça kırığı 90'ı yılların başında 1,6 milyon iken 2050 yılında kalça kırığı insidansı yaklaşık 6 milyon olarak tahmin edilmektedir. ${ }^{[1,2]}$ Bu kırıklar kalça ekleminin anatomik yapısına göre kapsül içi ve kapsül dışı olmak üzere iki tipte görülmektedir: Kırığın kapsül içerisinde veya dışarısında oluşmasına bağlı olarak farklı tedavi yöntemleri uygulanmaktadır.

\section{KALÇA EKLEMININ ANATOMISi}

Kalça eklemi küre şeklinde bir eklem olup tüm eksenlerde hareket edebilme kabiliyetine sahiptir. Kapsül proksimalde asetabulum kenarından başlayıp ön tarafta linea intertrochanterica'ya arka tarafta crista intertrochanterica'nın yukarı-iç kısmına tutunur. Kapsül
The number of hip fractures due to osteoporosis is increasing in the aging world population. Like in other types of fractures, classifications have been made in order to better define the hip fracture condition, decide the treatment method to be applied, and create a common language. We can make use of existing classification systems when planning the treatment of an elderly hip fracture patient. However, none of the current classification systems can precisely indicate the treatment option that should be applied to a particular type of fracture. Because the role of the fracture type in deciding the type of treatment is insufficient alone, other additional factors such as the patient's age, functional status, and comorbid conditions are directly related to this process.

Key words: femoral neck fracture; intertrochanteric fracture; Garden classification; Evans classification

ön tarafta trochanter minor'a kadar uzanırken, arka tarafta fossa trochanterica'yı dışarıda bırakacak şekilde femur boynunun büyük kısmını içine alacak şekilde yerleşmiştir. Eklem kapsülünün etrafinda ve içerisinde hareketleri kısıtlayan ve eklem stabilitesini artıran bağ yapıları bulunmaktadır. ${ }^{[3]}$

\section{SINIFLANDIRMA YÖNTEMLERI}

Kalça kırıklarında da daha iyi tanımlamak, uygulanacak tedavi yöntemine karar verebilmek ve ortak bir dil oluşturmak adına sınıflamalar yapılmıştır. Kapsül içi kırıklar eklemin içerisinde gelişen femur boyun kırıkları ve femur başı kırıkları olarak iki alt tipe ayrılabilir. Bu bölümde, düşük enerjili travma ile oluşmaları sebebiyle yaşlı hastalarda sadece femur boyun kırıkları ele alınacaktır. Zira, femur başı kırıkları genellikle genç popülasyonda yüksek enerjili travma ile oluşmaktadır.

- Illetişim adresi: Uzm. Dr. Mustafa Yerli, SBÜ Prof. Dr. Cemil Taşçıŏlu Şehir Hastanesi, Ortopedi ve Travmatoloji Kliniği, Darülaceze Caddesi No: 27

Okmeydanı, Şişli, İstanbul Tel: 0505 - 6073804 e-posta: mustafayerli199@gmail.com

- Geliș tarihi: 18 Ocak 2021 Kabul tarihi: 27 Ocak 2021

ORCID iD: Mustafa Yerli, 0000-0002-2708-5812 • Hakan Gürbüz, 0000-0002-6437-5771 
Femur boyun kırıkları tarihsel süreçte farklı yöntemler kullanılarak sınıflandırılmıştır. Bunlar; Garden sınıflaması, Pauwels sınıflaması ve AO/OTA sınıflamasıdır (Şekil 1). ${ }^{[4-6]}$ Garden sınıflaması 1961 yılında tanımlanmış olup kırığın ayrışma miktarına göre yapılmıştır. ${ }^{[4]}$ Femur boyun kırıklarını dört tipe ayıran bu sınıflama, ortopedi ve travmatoloji literatüründe en sık kullanılan sınıflama sistemidir. Ancak bu sınıflama sisteminin zayıf noktası gözlemciler arası uyumun zayıf olmasıdır. ${ }^{[7-9]}$ Beimers ve ark., bu sınıflama sistemindeki grup 1 ve 2'yi ayrışma olmayan (stabil) grup; grup 3 ve 4'ü ayrışmış (instabil) grup olarak geliştirerek gözlemciler arası uyumda artışta mükemmel sonuca ulaşmışlardır. [10]

Pauwels ve ark., kırık hattının yer ile yaptığı açıyı ele alarak femur boyun kırıklarını üç farklı tipte sınıflamışlardır. ${ }^{[5]}$ Bu sınıflama sisteminde tip 1'den tip 3'e doğru gidildikçe kırık hattı daha dik hale geldiği için kırık instabilitesinde ve tedavi sonrası oluşabilecek komplikasyonlarda artış olduğu bildirilmiştir. ${ }^{[11]}$

AO/OTA sınıflama sisteminde ise her bir kemiğin ve bölgesinin numara ve harf karşılığı olup femur boynu
31B ile gösterilmektedir. ${ }^{[6]}$ Bu sınıflama sisteminde 3 ana alt gruba ayrılan femur boyun kırıkları ayrıca kendi içlerinde de alt gruplara ayrılmaktadır.

Kalçanın kapsül dışı kırıklarında ilk akla gelen ise pertrokanterik bölge kırıklardır. Trokanter major ile minör arasında oluşan pertrokanterik kırıklarda farklı sınıflama sistemleri mevcuttur. Bunlardan sık kullanılanları; Boyd ve Griffin sınıflaması, Evans sınıflaması ve AO/OTA sınıflamasıdır (Şekil 2). ${ }^{[6,12,13]}$

Boyd ve Griffin sınıflaması, 1949 yılında tanımlanmış olup kırığı dört tipe ayırmıştır. ${ }^{[12]} \mathrm{Bu}$ sistemde kırık redüksiyonunun sağlanması ve korunması ele alınmıştır. Aynı dönemde Evans, kendi sınıflandırma sistemini tanımlayıp bildirmiştir. ${ }^{[13]}$ Her iki sınıflandırmada da temelde kırık redüksiyonunun sağlanıp korunabilirliği ele alınarak stabil ve stabil olmayan tipler tanımlanmış ve bu tipler de kendi içlerinde alt tiplere ayrılmıştır.

AO/OTA sınıflama sisteminde ise pertrokanterik bölge $31 \mathrm{~A}$ olarak belirtilmiş olup üç gruba ayrılmıştır. ${ }^{[6]}$

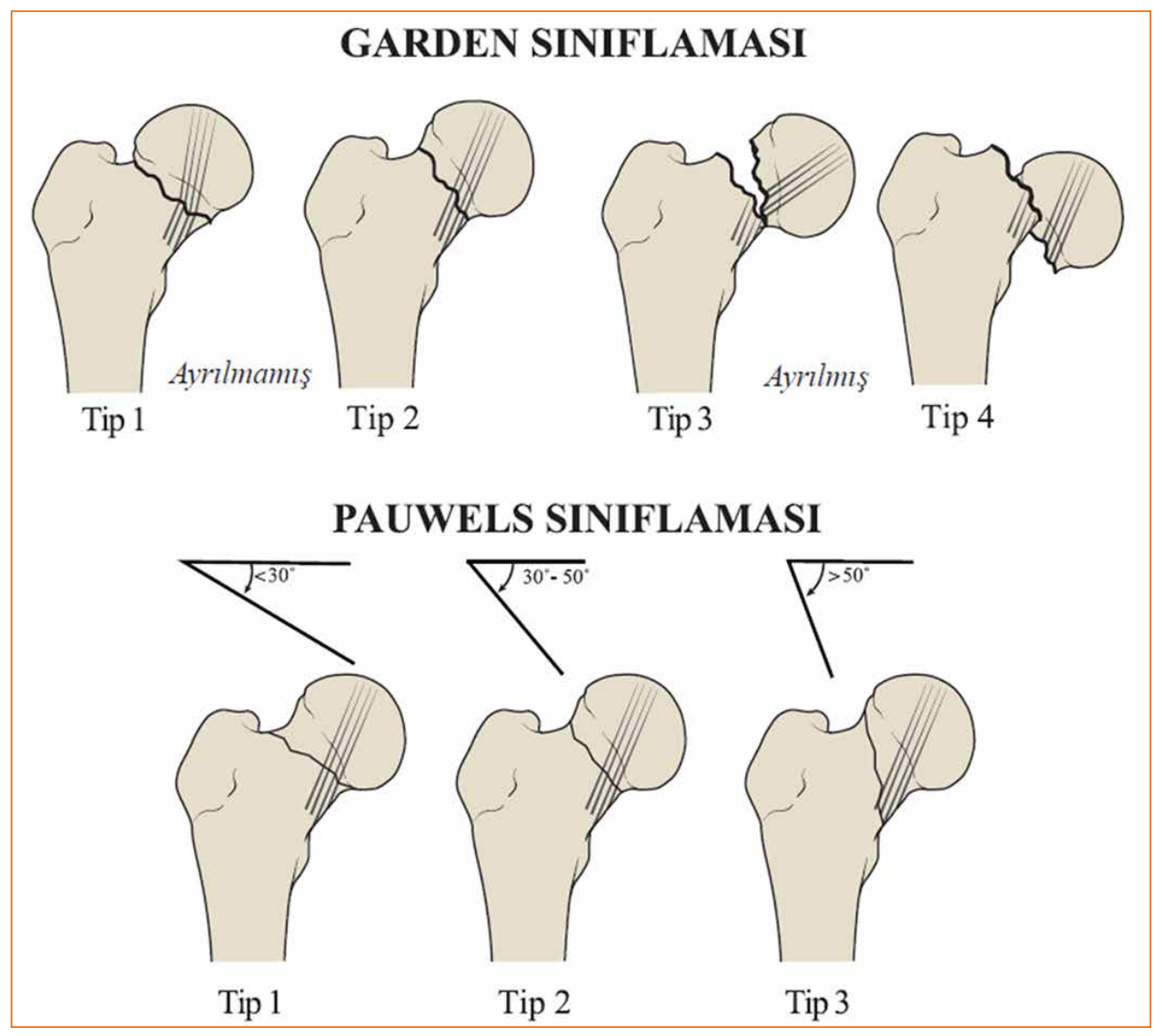

Şekil 1. Garden ve Pauwels sınıflama sistemleri..[4,5] 


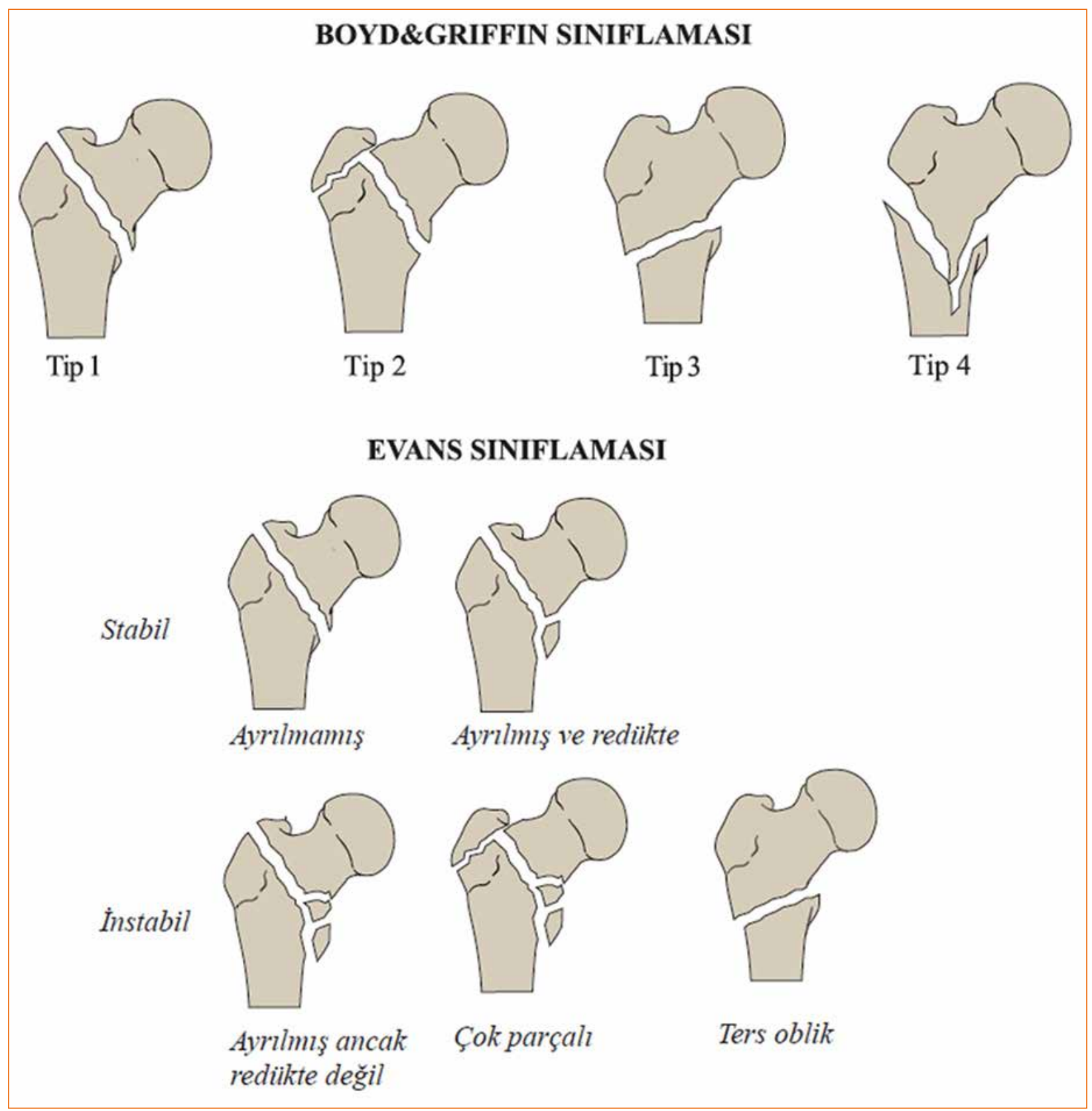

Şekil 2. Boyd\&Griffin ve Evans sınıflandırma sistemleri.[11,12]

\section{KIRIK MEKANIZMALARI}

Yaşıılarda kalça kırıkları çoğunlukla düşük enerjili travmalar sonucu oluşmaktadır. Doğrudan kalça yan tarafına düşme sonucu trokanter majore alınan travmanın femur boynuna aktarımı ile femur boyun kırıları oluşabilmektedir. Diğer mekanizma, ilgili ekstremitenin dış rotasyona zorlanması sonucu femur başının asetabulum içerisinde sabit kaldığı durumda gelişebilen femur boyun kırıklarıdır. Bu tip kırıklarda anterior kapsül ve iliofemoral bağın femur başını tutması nedeniyle posterior kortekste parçalanma ile birlikte görülmektedir. Bir diğer görüş ise osteoporotik kemiklerde fizyolojik yüklenmelerin kırık oluşturabilmesine dayanmaktadır. Teori, osteoporotik bireylerde var olan küçük kırık hatlarının hafif torsiyonel yaralanmalarla tam bir kırığa dönüşebilmesidir. Basit düşme sonucu oluştuğu düşünülen kırıkların da aslında o basit düşmenin sebebi olabilecekleri akılda tutulmalıdır. ${ }^{[14]}$ 


\section{UYGULANACAK TEDAVININ SEÇIMI}

Yaşlı kalça kırıklarında tedavinin en önemli amacı kırık öncesi fonksiyonelliğin bir an önce geri kazanılmasıdır. ${ }^{[15,16]}$ Bunu sağlayabilmek için iyi bir anamnez ve fizik muayenenin ardından hasta bir bütün olarak değerlendirilmeli, dar bir bakışla sadece proksimal femoral bölgeye odaklanmamak gereklidir. Bu yaş grubunda ek hastalıkların oldukça fazla görülmesi medikal açıdan ayrıntılı bir değerlendirme yapılması ve gerekli hallerde ilgili branş hekimlerine danışılarak tedavilerinin düzenlenmesi oldukça önemlidir. Hastaya uygulanacak tedavi her hasta için özel olmakla beraber, bazı temel etmenler karar vermede yol gösterici olmaktadır. Bu etmenler hastanın yaşı, fonksiyonel kapasitesi, ek hastalıkları, kırık tipi ve kemik kalitesi olarak sıralanabilir. Bu faktörler göz önüne alınarak uygulanacak tedaviye karar verilmelidir. Çünkü bu yaş grubundaki hastalarda tedavinin amacı olan erken hareket kazandırma hedefiyle verilecek tedaviye bağlı gelişebilecek komplikasyonlar oldukça ciddi sonuçlar doğurabilmektedir.

\section{SONUÇ}

Yaşlı kalça kırıklı bir hastanın tedavisini planlarken mevcut sınıflama sistemlerinden yararlanmaktayız. Örneğin femur boyun kırıklarında Garden sınıflamasına göre ayrışma olmayan kırıklarda osteosentez uygulamaları daha ön planda iken, ayrışmış kırıklarda artroplasti seçenekleri gündeme gelebilmektedir. ${ }^{[16,17]}$ Ayrışmış femur boyun kırıklarında kullanacağımız artroplasti tipi ise hastanın genel durumuna, kemik kalitesine, aktivite düzeyine ve yaşam beklentisine göre değişmektedir. ${ }^{[18,19]}$ Benzer şekilde, stabilite durumuna göre yapılmış bir sınıflamanın kullanıldığı intertrokanterik femur kırıklarının tedavilerinin kararında hastayla ilgili ek risk faktörleri de göz önüne alınmaktadır. ${ }^{[12,13]}$ Diğer taraftan, redüksiyonu sağlamanın ve korumanın mümkün olmadığı durumlarda tedavi yöntemi tamamen değişebilmektedir. ${ }^{[20]}$ Zira yalnızca kırık şeklinin tedavi yöntemine karar vermedeki rolü tek başına yeterli olmayıp, hastanın yaşı, fonksiyonel durumu, ek hastalıkları gibi diğer faktörler de bu süreçle doğrudan ilişkilidir.

\section{KAYNAKLAR}

1. Cooper C, Campion G, Melton LJ 3rd. Hip fractures in the elderly: a world-wide projection. Osteoporos Int 1992;2(6):285-9. Crossref

2. Dhanwal DK, Dennison EM, Harvey NC, Cooper C. Epidemiology of hip fracture: Worldwide geographic variation. Indian J Orthop 2011;45(1):15-22. Crossref

3. Arıncı K, Elhan A. Anatomi, 4. Baskı. Ankara: Güneş Kitabevi; 2006.
4. Garden RS. Low-angle fixation in fractures of the femoral neck. J Bone Joint Surg Br 1961;43-B(4):647-63. Crossref

5. BartonícekJ. Pauwels' classification of femoral neck fractures: correct interpretation of the original. J Orthop Trauma 2001;15(5):358-60. Crossref

6. Meinberg EG, Agel J, Roberts CS, Karam MD, Kellam JF. Fracture and Dislocation Classification Compendium - 2018. J Orthop Trauma 2018;32 Suppl 1:S1-10. Crossref

7. Frandsen PA, Andersen E, Madsen F, Skjødt T. Garden's classification of femoral neck fractures. An assessment of inter-observer variation. J Bone Joint Surg $\mathrm{Br}$ 1988;70$B(4): 588-90$. Crossref

8. Parker MJ. Garden grading of intracapsular fractures: meaningful or misleading? Injury 1993;24(4):241-2. Crossref

9. Kazley JM, Banerjee S, Abousayed MM, Rosenbaum AJ. Classifications in Brief: Garden Classification of Femoral Neck Fractures. Clin Orthop Relat Res 2018;476(2):441-5. Crossref

10. Beimers L, Kreder HJ, Berry GK, Stephen DJ, Schemitsch EH, McKee MD, Jaglal S. Subcapital hip fractures: the Garden classification should be replaced, not collapsed. Can J Surg 2002;45(6):411-4. https://www.ncbi.nlm.nih.gov/pmc/ articles/PMC3684654/

11. Shen M, Wang C, Chen H, Rui YF, Zhao S. An update on the Pauwels classification. J Orthop Surg Res 2016;11(1):161. Crossref

12. Boyd HB, Griffin LL. Classification and treatment of trochanteric fractures. Arch Surg 1949;58(6):853-66. Crossref

13. Evans EM. The treatment of trochanteric fractures of the femur. J Bone Joint Surg Br 1949;31-B(2):190-203. Crossref

14. Keating JF. Femoral neck fractures. In: Court-Brown $C M$, Heckman JD, McQueen MM, Ricci WM, Tornetta P 3rd, McKee MD, editors. Rockwood and Green's Fractures in Adults. Philadelphia: Wolters Kluwer Health/Lippincott Williams \& Wilkins; 2015. p.2031-74.

15. Dai Z, Li Y, Jiang D. Meta-analysis comparing arthroplasty with internal fixation for displaced femoral neck fracture in the elderly. J Surg Res 2011;165(1):68-74. Crossref

16. Blomfeldt R, Törnkvist $H$, Ponzer S, Söderqvist A, Tidermark J. Displaced femoral neck fracture: comparison of primary total hip replacement with secondary replacement after failed internal fixation: a 2-year follow-up of 84 patients. Acta Orthop 2006;77(4):638-43. Crossref

17. Ju DG, Rajaee SS, Mirocha J, Lin CA, Moon CH. Nationwide Analysis of Femoral Neck Fractures in Elderly Patients: A Receding Tide. J Bone Joint Surg Am 2017;99(22):1932-40. Crossref

18. Avery PP, Baker RP, Walton MJ, Rooker JC, Squires B, Gargan MF, Bannister GC. Total hip replacement and hemiarthroplasty in mobile, independent patients with a displaced intracapsular fracture of the femoral neck: a sevento ten-year follow-up report of a prospective randomised controlled trial. J Bone Joint Surg Br 2011;93-B(8):1045-8. Crossref

19. Blomfeldt R, Törnkvist H, Eriksson K, Söderqvist A, Ponzer S, Tidermark J. A randomised controlled trial comparing bipolar hemiarthroplasty with total hip replacement for displaced intracapsular fractures of the femoral neck in elderly patients. J Bone Joint Surg Br 2007;89-B(2):160-5. Crossref

20. Görmeli G, Korkmaz MF, Görmeli CA, Adanaş C, Karataş T, Simşek SA. Comparison of femur intertrochanteric fracture fixation with hemiarthroplasty and proximal femoral nail systems. Ulus Travma Acil Cerrahi Derg 2015;21(6):503-8. Crossref 